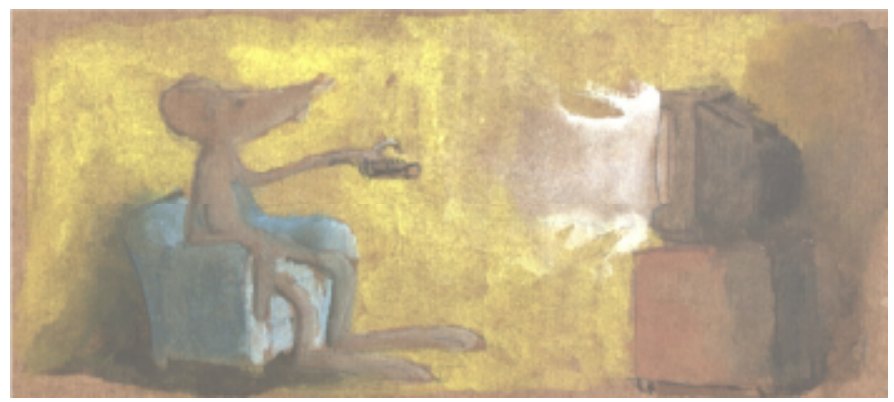

Ilustração Alessandro Lima

\title{
As incompletudes da televisão abrem espaço para a imaginação do telespectador
}

\section{Arlindo Machado por Mônica Ramos}

Arlindo Machado é professor de Comunicação e Semiótica da PUC-SP e da USP, é autor de vários livros sobre televisão, vídeo, cinema e fotografia, foi curador de exposições artísticas, além de ter organizado mostras de arte eletrônica e dirigido filmes de curtametragem.

Mônica Ramos é membro do Programa A tela e o texto e mestranda em Teoria da Literatura da Faculdade de Letras/UFMG.

Mônica Ramos - Fale sobre a especificidade da televisão e em que esta mídia pode contribuir para a literatura.

Arlindo Machado - Não é função primordial da televisão contribuir para o desenvolvimento da literatura ou de qualquer outra mídia ou arte. A televisão deve, em primeiro lugar, contribuir para o desenvolvimento da própria televisão, em termos de linguagem, formatos e gêneros, densidade de conteúdos, inserção crítica na vida social do país etc. Esforços que são dispendidos por parte das elites para colocar a televisão a serviço da educação ou da difusão da alta cultura me parecem ingênuos e condenados ao fracasso. A televisão é um meio de expressão em si e deve ser valorizado (ou criticado) pelo que ela efetivamente é, em sua autonomia e especificidade. O que não impede que, em certas circunstâncias, ela vá buscar na literatura temas e modelos, que serão em seguida traduzidos para a sua linguagem. Mas o objetivo não deve ser promover a literatura e sim criar formas criativas de diálogo entre 
os dois meios de expressão. Ultimamente, temos visto bons exemplos de utilização da literatura para desenvolver formatos mais avançados de televisão. Contos da Meia Noite na TV Cultura e Cena Aberta na TV Globo são bons exemplos dessa tendência.

\section{Uma adaptação de uma obra literária pode instigar o telespectador a ler o livro?}

Há algumas décadas, existia no Brasil uma revista de histórias em quadrinhos (chamada Edição Maravilhosa), que se dedicava a adaptações de clássicos da literatura para o formato gibi. No final de cada volume, havia uma advertência que dizia mais ou menos assim: "As adaptações de romances para a Edição Maravilhosa são apenas um aperitivo, um deleite para o leitor. Se você gostou, procure ler o próprio livro, adquirindo-o em qualquer livraria. E monte a sua própria biblioteca." A verdade é que muita gente se iniciou na literatura lendo as adaptações para histórias em quadrinhos da Edição Maravilhosa, assim como muita gente se iniciou na música erudita ouvindo adaptações para orquestras populares ou em artes plásticas colecionando os fascículos de reproduções de pinturas dos grandes mestres vendidos em bancas. Em televisão, há um fato já constatado que é o incremento gigantesco da venda de um livro quando ele é adaptado para série ou minissérie. Portanto, a resposta é positiva. Cinema e televisão podem promover o consumo de livros, embora isso não deva ser a sua função principal. Os discos também podem promover o interesse pela boa música (as pessoas que compram discos acabam também indo aos concertos ao vivo). O único problema a considerar é o tempo. Com a ampliação dos meios de comunicação, os leitores têm cada vez menos tempo para ler livros, pois uma parte do período que seria dedicado à leitura acaba sendo ocupado pela recepção de outros meios.

\section{Qual é a importância estética dos videoclipes hoje? Você acredita que a sua influência em outras mídias (filmes, propagandas e até literatura) é interessante?}

O videoclipe é um dos gêneros mais genuinamente televisuais, além de ser o espaço de experimentação em televisão, onde conquistas das artes de vanguarda acabam sendo assimiladas e encontram um público muito mais amplo. Nem tudo é bom, é claro, mas em nenhum outro formato de $\mathrm{TV}$ se encontram trabalhos experimentais na mesma proporção que no videoclipe. Além disso, o videoclipe é o gênero mais desembolorado da TV. Enquanto outros formatos (como telejornal, telenovela, talk show) são muito codificados e deixam pouca margem para improvisação ou renovação, o videoclipe não tem nenhuma forma rígida estabelecida a priori. A rigor, pode-se fazer qualquer coisa 
num videoclipe, bastando para isso que os realizadores tenham imaginação e criatividade. A linguagem do videoclipe, sem dúvida, influência outros meios e outros formatos, mas também é influenciada por eles.

\section{Quais são os interditos da televisão atualmente? Que barreiras você acha que ela tem que romper?}

o principal problema da televisão (sobretudo da brasileira) é a préconcepção de espectador por parte dos homens que a fazem. Quem escreve um livro imagina um leitor inteligente, mas quem faz televisão quase que invariavelmente imagina um espectador estúpido. E quase toda a programação de televisão é concebida em função do mais estúpido dos espectadores. Por exemplo: o repertório de palavras que se pode usar na TV é sempre o menor possível (não mais que 500 palavras), pois os produtores consideram que um vocabulário mais rico ficaria ininteligível ao estúpido que eles imaginam na frente da TV. Portanto, a televisão criou o seu próprio limite: ela não se permite trabalhar com um espectador mais exigente e mais crítico. Por outro lado, falta crítica de televisão. O que existe nos jornais é apenas uma crônica de TV, sempre mais próxima da fofoca do que da análise. Muitas pessoas se baseiam nas críticas de cinema para decidir o filme que vão ver, mas ninguém se baseia em críticas de TV (até porque elas não existem) para decidir o que ver na tela pequena. Falta-nos também bons modelos de análise de programas de TV e revistas especializadas que acompanhem criticamente a produção. Faltam cursos específicos sobre televisão nas escolas. Em decorrência de todas essas lacunas, não se desenvolve pensamento crítico sobre a TV e nos tornamos meio que embrutecidos diante dela.

\section{Fale sobre a importância da sinestesia nas produções televisivas!}

Televisão é uma linguagem audiovisual e, portanto, invoca pelo menos dois sentidos: a visão e a audição. Chamamos sinestesia a evocação de um sentido por um estímulo destinado a outro. Por exemplo: um som que evoca uma cor ou uma imagem que evoca um timbre sonoro. Por extensão, podemos também chamar de sinestesia o entrelaçamento de dois estímulos sensoriais, ou seja, a produção de uma imagem e de um som que sejam tão absolutamente necessários um ao outro, a ponto de não fazer sentido aquele exato som sem aquela exata imagem e viceversa. A televisão tem produzido bons exemplos de sincronização imagem-som, sobretudo em alguns videoclipes e programas musicais. Um dos mais belos exemplos de evocação sinestésica em televisão é a série canadense Yo-Yo Ma Inspired by Bach (1997), produzida por Niv Fichman, em que diferentes artistas (um cineasta, um coreógrafo, uma 
paisagista, um gravurista, um ator de kabuki e um casal de dançarinos no gelo) são desafiados a imaginar equivalentes visuais ou moto-visuais para cada uma das suítes para violoncelo de Bach.

Comente um pouco sobre o potencial latente da televisão, em novidades como TV digital e educação à distância!

A TV digital significa o casamento da televisão com o computador. Produzirá mudanças profundas principalmente na forma como se vê TV. A televisão não terá mais horários pré-estabelecidos, cada espectador montará sua programação como e quando lhe parecer melhor. Haverá também a possibilidade de compor programas mistos, de tipo hipermídia. Por exemplo, uma série ou minissérie de tipo histórico poderá ter textos de aprofundamento com explicações sobre a época e que seriam baixados pelo espectador caso ele quisesse mais detalhes sobre o período. Nesse caso, uma minissérie como $A$ Muralha poderia incluir o próprio livro em formato digital, que o espectador/leitor poderia ler na tela ou imprimir em papel. Uma coisa pelo menos será certa: com a TV digital, o espectador terá mais coisas para ler, além do material audiovisual. Ela poderá ajudar a recuperar o hábito de ler e escrever, como o computador já o vem fazendo.

Você apostou na televisão interativa, que, embora tecnicamente possível, teria que ceder a uma televisão unidirecional. você vê alguma chance de que o espectador realmente comece a interagir com as emissoras?

A interação não é apenas um problema de ordem tecnológica (embora seja também isso), mas principalmente de ordem conceitual e até mesmo política. Quem está interessado na participação do espectador? E, mesmo admitindo que esse interesse existe, que tipo de participação se espera do espectador? Apenas que ele escolha entre as opções de um menu, ou que ele direcione ativamente o desenvolvimento de uma ação ou trama? Em meu modo de ver, a verdadeira interatividade significaria aceitar a opinião do espectador como constitutiva da televisão, não apenas em termos de rating (Ibope), mas de co-participante do "fazer televisão". Mas isso é coisa que só se pode conquistar no plano político, não no plano técnico.

Você diz que a televisão seria mais autêntica que o cinema, entre outros aspectos, por mostrar o próprio processo de produção, ao contrário do cinema que, de certa maneira, estaria enganando 0 espectador devido ao "mascaramento das técnicas construtivas". A televisão não tem também suas mentiras? 
Há pouco tempo, as televisões européias exibiram um "documentário" chamado Opération Lune (The Dark Side of the Moon, na versão em inglês) que tentava provar, com argumentos e depoimentos dos próprios protagonistas, que os americanos jamais estiveram na lua e que tudo não passou de uma farsa. O "documentário" era absolutamente convincente, mas ao final se revela que tudo era falso: os depoimentos foram manipulados e adulterados, tudo foi um efeito de edição e os truques utilizados foram revelados ao final do programa. Portanto, o próprio "documentário" se desmascara e, ao fazê-lo, mostra o poder que tem 0 audiovisual de criar as suas próprias verdades. Mas, ao fazê-lo, ele não deixa de criar também uma zona de dúvida, colocando em questão a conquista da Lua pelos americanos. Mesmo que forjados, os argumentos invocados podem encerrar alguma verdade, de tal forma que após ver esse programa fica difícil deixar de pensar na conquista espacial como um truque cinematográfico. Claro que não é sempre que a televisão se revela de forma metalingüística como nesse caso, mas quando o faz o resultado é perturbador.

Você afirmou que sistemas de baixa definição como a televisão exigiriam um espectador mais participativo e crítico do que os de alta definição como o cinema. A atitude do espectador realmente depende de uma questão técnica, no caso, da baixa ou alta definição?

Na verdade o argumento é de Marshall McLuhan; eu apenas o comento e procuro dar-lhe uma maior amplitude. McLuhan, sim, fica apenas no plano técnico, mas eu procuro pensar a questão da participação do espectador para além desse limite. Naturalmente, no livro A arte do vídeo, eu analiso essa questão de um ponto de vista mais psicológico e cognitivo: as incompletudes da televisão poderiam abrir espaço para a imaginação e a intervenção construtiva do espectador. Mas resta a questão da participação efetiva do espectador na própria construção dos programas, que discutimos numa resposta acima. Essa não pode ser corretamente equacionada senão no plano político.

\section{Que livros você está escrevendo agora? Como tem visto a questão da televisão na atualidade?}

Acabo de fazer uma compilação de textos escritos entre 1968 e 1984, tratando de vários temas, inclusive televisão. O livro se chama os anos de chumbo: mídia, poética e ideologia no período de resistência ao autoritarismo militar e deverá sair em março pela Editora Sulina (de Porto Alegre). Neste momento, estou trabalhando em meu novo livro, que se chamará o sujeito na tela: modos de enunciação no cinema e no ciberespaço, que 
espero completar em meados do ano e editar pela Paulus (de São Paulo). Mais a longo prazo, tenho um projeto de um livro de análise de programas de televisão que está prometido para a coleção Estudios de televisión, da Editorial Gedisa, de Barcelona. Será publicado diretamente em espanhol e terá o título Análisis del programa televisivo.

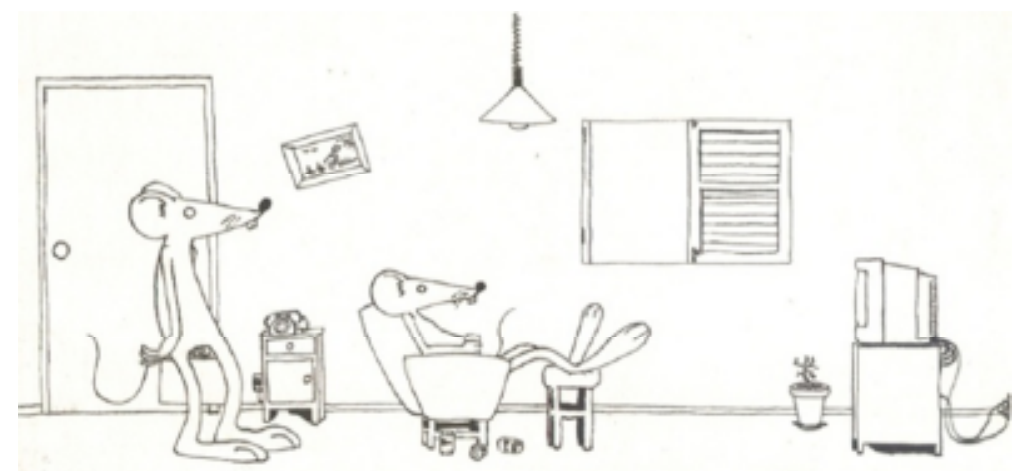

Ilustração Alessandro Lima 